\title{
THE INFLUENCE OF INDIVIDUAL CHARACTERISTICS AND JOB SATISFACTION TOWARD MOTIVATION BY THE SABHARA PERSONNEL OF PADANG PARIAMAN POLICE
}

\author{
Fii Syatir Radiah, Maria Magdalena \\ STIE “KBP” Padang
}

\begin{abstract}
This research has a formulation of the problem: 1. The influence of individual characteristics on personnel motivation against sabhara polres padang pariaman, 2. Influence motivation towards job satisfaction at polres sabhara personnel padang pariaman. The data collection of this research through the spreading of questionnaires to 32 respondents by using total sampling technique, where all the population is sampled. Based on the result of research indicate that individual characteristic variable have positive and significant effect to motivation because t-hit value $(0,620)$ with significance value 0,540 bigger than level signifikan signifikan 0,05 and job satisfaction variable have positive and significant influence to motivation because $t$ - 2,678) with a significance value of 0.012 smaller than the 0.05 significance level. While the significance value of $F$ test results of 0.004 means the significance is smaller than 0.05. This indicates that there is a positive and significant influence simultaneously or simultaneously between individual characteristics and job satisfaction toward motivation by the sabhara personnel of padang pariaman police.
\end{abstract}

Keywords: Individual Characteristics, Job Satisfaction And Motivation. 


\section{PENDAHULUAN}

Seiring dengan globalisasi dan perkembangan teknologi yang terjadi saat ini perusahaan harus menciptakan sumber daya manusia yang efektif dan efisien, karena sumber daya manusia merupakan aset terbesar untuk kelangsungan hidup perusahaan saat ini maupun dimasa yang akan datang.

Salah satu kegiatan yang paling penting dalam organisasi / perusahaan, dimana sumber daya manusia adalah kegiatan mendapatkan orang-orang yang tepat, seperti halnya karakteristik individu, baik perusahaan maju maupun perusahaan berkembang, dalam pendekatan sumber daya manusia berarti semua dan setiap organisasi/perusahaan harus sanggup menciptakan rasa aman dan kepuasan dalam bekerja (Quality of work life) sehingga menimbulkan motivasi kerja yang tinggi terhadap setiap karyawan dari perusahaan tersebut.

Menurut Rivai (2008) hasil penilaian motivasi dapat menunjukkan apakah sumber daya manusia telah memenuhi tuntutan yang dikehendaki perusahaan, baik dilihat dari sisi kualitas maupun kuantitas. Informasi dalam penilai motivasi karyawan merupakan refleksi dari berkembang atau tidaknya suatu perusahaan.

Hal ini dapat diartikan bahwa penurunan atau peningkatkan eksistensi merupakan perkembangan dari suatu perusahaan.

Dengan adanya perkembangan ini ternyata tidak lepas dari motivasi karyawan yang berkualitas. Salah satu sumber masalah yang dihadapi perusahaan berasal dari sumber daya manusia di perusahaan tersebut yang kurang optimal dalam bekerja sehingga menyebabkan produktivitas perusahaan menurun dan tidak mencapai target. Kecenderungan penurun produktivitas perusahaan salah satunya diakibatkan oleh prilaku kerja yang sering bolos, tertidur saat jam kerja sedang aktif, atau pulang lebih awal dari jam kerja. Prilaku malas pada karyawan ini muncul dari ketidakpuasan karyawan yang berkaitan dengan pemenuhan kebutuhan, (Gustisyah, 2009).

Salah satu faktor untuk meningkatkan kepuasan kerja adalah motivasi karena dengan adanya motivasi akan mendorong semangat kerja, inspirasi dari aktifitas kerja karyawan untuk bekerja lebih baik agar tercapai tujuan organisasi (Robbins/Judge, 2009).

Pentingnya motivasi karyawan dalam pembentukan karakterisitik individu maka pimpinan Sabhara Polres Padang Pariaman memberikan serangkaian usaha untuk meningkatkan produktivitas dalam bekerja secara efesien dan efektif agar sesuai dengan kebijakan yang telah ditetapkan. Selain itu diharapkan baik secara sistem maupun operasionalnya pada saat nanti karyawan akan memiliki perasaan aman dan nyaman dalam menjalankan tugas, dengan kondisi ini diharapkan kepuasan kerja karyawan pada masing-masing pekerjaannya akan meningkat.

Penelitian ini bertujuan untuk mengetahui pengaruh karakteristik individu dan kepuasan kerja terhadap motivasi pada personil sabhara polres padang pariaman.

\section{KAJIAN TEORI}

\section{Karakteristik Individu}

Thoha (2007) menyatakan karakteristik individu sebagai proses yang menjelaskan bahwa individu 
membawa kedalam tatanan organisasi, kemampuan, kepercayaan pribadi, penghargaan kebutuhan dan pengalaman masa lalunya. Ini semua adalah karakteristik yang dimilki individu dalam melakukan usaha untuk memasuki suatu lingkungan baru yakni organisasi pada tempat karyawan tersebut.

Menurut Husein dan Hady (2012) Mengungkapkan bahwa terdapat beberapa faktor yang mempengaruhi karakteristik individu yaitu: kemampuan, sikap dan keahlian.

Menurut Arief Subyantoro (2009) menyebutkan bahwa setiap orang mempunyai pandangan, tujuan, kebutuhan dan kemampuan yang berbeda satu sama yang lain. Perbedaan ini terbawa dalam dunia kerja, yang akan menyebabkan kepuasan satu dengan yang lain berbeda ketika bekerja ditempat yang sama. Arief Subyantoro menyebutkan indikator karakteristik individu sebagai berikut: kemampuan, nilai, sikap dan minat.

\section{Kepuasan Kerja}

3. Kepuasan kerja merupakan bentuk perasaan seseorang terhadap pekerjaannya, situasi kerja dan hubungan dengan rekan kerja. Dengan demikian kepuasan kerja merupakan sesuatu yang penting untuk dimiliki oleh seorang, karyawan, dimana mereka dapat berinteraksi dengan lingkungan kerjanya sehingga pekerjaan dapat dilaksanakan dengan baik dan sesuai dengan tujuan perusahaan.

Menurut Handoko (2000:193)

"Kepuasan kerja (job satisfaction) adalah keadaan emosional yang menyenangkan atau tidak menyenangkan bagaimana para karyawan memandang pekerjaan mereka. Kepuasan kerja mencerminkan perasaan seseorang terhadap pekerjaannya .

Menurut hasibuan (2008) kepuasan kerja dipengaruhi oleh banyak faktor antara lain: balas jasa yang adil dan layak, penempatan yang tepat dan sesuai dengan keahlian, suasana dan lingkungan kerja, berat ringannya pekerjaan yang dilakukan seseorang, eralatan dan prasarana penunjang dalam bekerja dan sikap pimimpin dalam kepemimpinan atas tanggungjawab yang dimilikinya akan mempengaruhi kepuasan kerja karyawan.

Menurut Luthans (2006) kepuasan kerja dalam suatu perusahan adalah sangat penting. Karena setiap perusahaan akan mengetahui bagaimana kriteria seorang karyawan yang diinginkan oleh perusahaan. Dimana kriteria tersebut memiliki beberapa indikator sebagai berikut: pekerjaan itu sendiri, atasan, teman kerja, promosi, dan gaji atau upah.

\section{Motivasi}

Motivasi adalah sekelompok faktor yang menyebabkan individu berprilaku dalam cara-cara tertentu (Grifin, 2003).Motivasi merujuk pada kekuatan-kekuatan internal dan eksternal seseorang yang membangkitkan antusiasme dan perlawanan untuk melakukan serangkaian tindakan tertentu. Motivasi karyawan mempengaruhi kinerja, dan sebagian tugas manajer adalah menyalurkan motivasi menuju pencapaian tujuan-tujuan organisasi. 
Dalam penelitian ini peneliti mengunakan indikator motivasi dari teori Maslow. Teori hierarki kebutuhan dari Abraham Maslow Sofyandi dan Garniwa (2007), terdiri dari : kebutuhan fisiologi, kebutuhan rasa aman, kebutuhan social, kebutuhan penghargaan dan kebutuhan aktualisasi.

\section{Hipotesis}

H1: Diduga karakteristik individu berpengaruh signifikan terhadap motivasi karyawan pada personil sabhara polres padang pariaman.

H2: Diduga kepuasan kerja berpengaruh signifikan terhadap motivasi karyawan pada personil sabhara polres padang pariaman.

\section{METODE PENELITIAN}

\section{Jenis Penelitian}

Jenis penelitian yang digunakan dalam penelitian ini adalah penelitian kuantitatif. Menurut Sugiyono (2014) penelitian kuantitatif digunakan untuk meneliti pada populasi atau sampel tertentu.

\section{Penentuan Sampel}

Teknik pengambilan sampel pada penelitian ini adalah total sampling. (Sugiyono, 2007) Total sampling adalah teknik pengambilan sampel diamana jumlah populasi sama dengan jumlah sampel. Alasan mengambil teknik total sampling karena jumlah populasi yang kurang dari 100 dan seluruh populasi dijadikan sampel penelitian yang berjumlah 32 personil.

\section{Jenis dan Sumber Data}

Jenis data dalam penelitian ini adalah data primer dan sekunder seperti, menyebarkan kuesioner berupa pertanyaan tertulis, dan dokumentasi seperti melihat atau mencatat dokumen-dokumen perusahaan yang berkaitan dengan penelitian.

One-Sample Kolmogorov-Smirnov Test

\begin{tabular}{|c|c|c|}
\hline & & $\begin{array}{c}\text { Unstandardize } \\
\text { d Residual }\end{array}$ \\
\hline \multicolumn{2}{|l|}{$\mathrm{N}$} & 32 \\
\hline \multirow{2}{*}{$\begin{array}{l}\text { Normal } \\
\text { Parameters }\end{array}$} & Mean & .0000000 \\
\hline & Std. Deviation & 1.18277022 \\
\hline \multirow{2}{*}{$\begin{array}{l}\text { Most } \\
\text { Extreme }\end{array}$} & Absolute & .101 \\
\hline & Positive & .095 \\
\hline 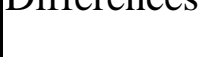 & Negative & -.101 \\
\hline \multicolumn{2}{|c|}{ Kolmogorov-Smirnov Z } & .572 \\
\hline \multicolumn{2}{|c|}{ Asymp. Sig. (2-tailed) } & .899 \\
\hline \multicolumn{2}{|c|}{$\begin{array}{l}\text { a. Test distribution is } \\
\text { Normal. }\end{array}$} & \\
\hline
\end{tabular}

HASIL PENELITIAN

1. Uji Asumsi Klasik

a. Uji Normalitas

Uji normalitas adalah pengujian tentang kenormalan distribusi data. Penggunaan uji normalitas karena pada analisis statistik parametik, asumsi yang harus dimiliki oleh data adalah bahwa data tersebut harus terdistribusi secara normal. Maksud data terdistribusi secara normal adalah bahwa data akan mengikuti bentuk distribusi normal. 
Berdasarkan hasil uji normalitas diketahui nilai signifikansi 0,899 lebih besar dari batas signifikannya yaitu 0,05 . Maka dapat disimpulkan bahwa nilai residual berdistribusi normal.

\section{b. Uji Multikolinearitas}

Uji ini bertujuan untuk menguji apakah model regresi ditemukan adanya korelasi antar variabel bebas (independen).Model regresi yang baik seharusnya tidak terjadi korelasi di antara variabel bebas. Jika variabel bebas saling berkorelasi, maka variabel-variabel ini tidak ortogonal.

\begin{tabular}{|l|l|l|}
\hline $\begin{array}{l}\text { Variable } \\
\text { Penelitian }\end{array}$ & VIF & Tolerance \\
\hline $\begin{array}{l}\text { Karakteristik } \\
\text { Individu } \\
(\mathrm{X} 1)\end{array}$ & 1.435 & 0.697 \\
\hline $\begin{array}{l}\text { Kepuasan } \\
\text { Kerja (X2) }\end{array}$ & 1.435 & 0.697 \\
\hline
\end{tabular}

Dari hasil yang didapatkan bahwa semua nilai VIF <10 ini berarti tidak terjadi multikolonieritas. Maka kesimpulannya bahwauji multikolinearitas terpenuhi.

\section{c. Uji Heteroskedastisitas}

Uji heteroskedastisitas menghasilkan grafik pola penyebaran titik (scatterplot).

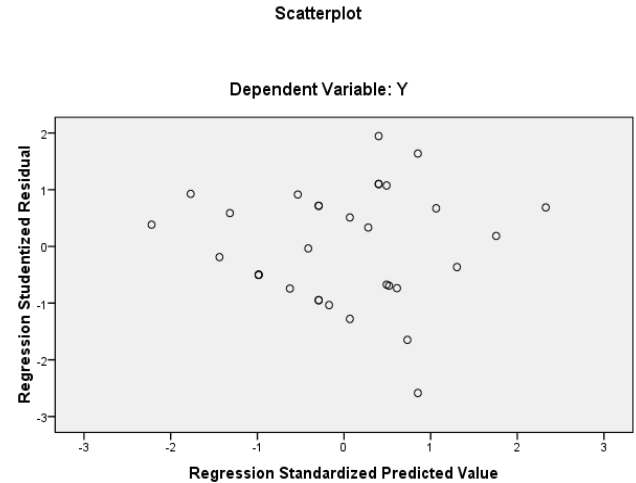

Dari gambar diatas dapat dilihat bahwa tidak ada pola yang jelas serta titik - titik menyebar diatas dan dibawah angka 0 pada sumbu y, maka dapat disimpulkan tidak terjadi heteroskedastisitas.

\section{Hasil Regresi Berganda}

persamaan regresi linear berganda untuk pengaruh karakteristik individu dan kepuasan kerja terhadap motivasi pada personil sabhara polres padang pariaman adalah sebagai berikut :

\section{$\mathbf{Y}=\mathbf{a}+\mathbf{b}_{1} \mathbf{X}_{1}+\mathbf{b}_{2} \mathbf{X}_{\mathbf{2}}+\mathbf{e}$}

$\mathrm{Y}=6.988+0.097 \mathrm{X} 1+0,364 \mathrm{X} 2+\mathrm{e}$

persamaan regresi diatas memiliki pengertian sebagai berikut :

Koefisien regresi karakteristik individu (X1) bernilai positif yaitu 0,097 . Hal ini berarti setiap peningkatan katakteristik individu sebesar 1 satuan akan mengakibatkan peningkatan motivasi pada personil sabhara polres padang pariaman adalah 0,097 satuan dengan asumsi variabel lain selain karakteristik individu adalah tetap atau tidak mengalami perubahan.

1. Koefisien regresi kepuasan kerja (X2) bernilai positif yaitu 0,364. Hal ini berarti setiap peningkatan kepuasan kerja sebesar 1 satuan akan mengakibatkan peningkatan 
motivasi pada personil sabhara polres padang pariaman adalah 0,364 satuan dengan asumsi variabel lain selain kepuasan kerja adalah tetap atau tidak mengalami perubahan.

Kerja) dengan koefisien 0,364 dari persamaan tersebut dilihat bahwa variabel Karakteristik individu dan kepuasan kerja berpengaruh positif terhadap motivasi. Dimana persamaan regresi dua predictor X1 dan X2 bertanda positif, maka dapat diartikan bahwa satu satuan skor karakteristik dan kepuasan kerja akan dipengaruhi oleh motivasi. Karakteristik individu sebesar 0,097 dan kepuasan kerja sebesar 0,364 pada konstanta 6,988.

\section{Hasil Uji Determinasi}

\section{Model Summary}

\begin{tabular}{|c|c|c|c|c|}
\hline Model & $\mathrm{R}$ & $\begin{array}{l}\text { R } \\
\text { Square }\end{array}$ & $\begin{array}{l}\text { Adjusted } \\
\text { R Square }\end{array}$ & $\begin{array}{l}\text { Std. } \\
\text { Error of } \\
\text { the } \\
\text { Estimat } \\
\text { e }\end{array}$ \\
\hline 1 & $\begin{array}{l}.56 \\
3^{\mathrm{a}}\end{array}$ & .317 & .270 & 1.22288 \\
\hline
\end{tabular}

a. Predictors: (Constant), X2, $\mathrm{X} 1$

nilai Adjusted $\mathrm{R}$ Square yang mempunyai nilai 0,27 yang berarti pengaruh $\mathrm{X} 1, \mathrm{X} 2$, perubahan yang terjadi pada karakteristik individu dan kepuasan kerja dapat menjelaskan 27\% terhadap variasi perubahaan motivasi, artinya $73 \%$ dijelaskan oleh variabel lain yang ada di luar model, seperti kompensasi dan promosi.

\section{Hasil Uji Parsial (T)}

Berdasarkan hasil pengolahan data bahwa nilai signifikasi t-hitung $(0,620)$ dan nilai signifikansinya 0,540 . Hal ini berarti signifikasi lebih besar dari 0,05 . Hal ini menunjukkan ada pengaruh yang positif dan signifikan antara karakteristik individu terhadap motivasi. Jadi hipotesisnya Ho diterima Ha ditolak. Sedangkan signifikan antara kepuasan kerja terhadap motivasi adalah signifikasi thitung (2.678) dan nilai signifikansinya 0,012 . Hal ini berarti signifikasi lebih kecil dari 0,05. Jadi hipotesisnya Ho ditolak Ha diterima.

\section{Hasil Uji Simultan (F)}

Berdasarkan hasil pengolahan data bahwa nilai signifikasi $\mathrm{F}$ hasil pengujian sebesar 0,004 berarti signifikasi $\mathrm{F}$ lebih kecil dari 0,05. Hal ini menunjukkan ada pengaruh yang positif dan signifikan secara simultan/serempak antara karakteristik individu dan kepuasan kerja terhadap motivasi. Jadi hipotesisnya Ho ditolak Ha diterima.

\section{KESIMPULAN DAN SARAN kesimpulan}

1. Berdasarkan hasil pengolahan data dapat dilihat bahwa nilai signifikasi t-hitung $(0,620)$ dan nilai signifikansinya 0,540 . Hal ini berarti signifikasi lebih besar dari 0,05 . Hal ini menunjukkan ada pengaruh yang positif dan signifikan antara karakteristik individu terhadap motivasi. Jadi hipotesisnya Ho diterima Ha ditolak.

2. Berdasarkan hasil pengolahan data dapat dilihat bahwa nilai signifikasi t-hitung (2.678) dan nilai signifikansinya 0,012 . Hal ini berarti signifikasi lebih kecil dari 0,05 . Hal ini menunjukkan ada pengaruh yang signifikan antara kepuasan kerja terhadap motivasi. Jadi hipotesisnya Ho ditolak Ha diterima. 
3. Berdasarkan hasil pengolahan data dapat dilihat bahwa nilai signifikasi $\mathrm{F}$ hasil pengujian sebesar 0,004 berarti signifikasi $\mathrm{F}$ lebih kecil dari 0,05. Hal ini menunjukkan ada pengaruh yang positif dan signifikan antara karakteristik individu dan kepuasan kerja terhadap motivasi. Jadi hipotesisnya Ho ditolak Ha diterima.

\section{Saran}

1. Personil Sabhara Polres Padang Pariaman sebaiknya meningkatkan rasa kerjasama dengan sesama personil agar terciptanya lingkungan kerja yang harmonis, dan perlunya keterbukaan atasan kepada bawahan dalam hal pekerjaan dan menerima saransaran dan bawahan yang dapat meningkatkan efektifitas kerja.

2. Pihak manajemen Sabhara Polres Padang Pariaman juga harus ikut memberikan kesempatan kepada personilnya yang berprestasi untuk lebih maju lagi, baik dan jabatan, kesempatan untuk berkembang, penghargaan, pemberian insentif khusus dan lain-lain, sehingga personil betulbetul dapat berkarya lebih baik lagi.

3. Untuk meningkatkan kepuasan kerja personil maka pihak manajemen Sabhara Polres Padang Pariaman perlu memberikan kompensasi yang dapat memenuhi harapan personil sehingga personil termotivasi dan semangat dalam menjalankan pekerjaanya.

\section{DAFTAR PUSTAKA}

Ardana dkk. 2008. Perilaku Keorganisasian. Edisi Kedua. Graha Ilmu. Yogyakarta.

Agung Dwi Waluyo, Kusni Ingsih. 2014. Pengaruh Kepemimpinan, Kepuasan Kerja dan Motivasi kerja Terhadap Kinerja Karyawan Terminal Peti Kemas Semarang (TPKS) Pelabuhan Indonesia III Tanjungmas di Semarang.

Andy Setiawan, Tri Bodroati. 2012. Pengaruh Karakteristik Individu dan Faktor-Faktor Pekerjaan terhadap Motivasi Karyawan CV. Bitang Timur Semarang.

Arief Subyantoro, 2009. Pengaruh Karakteristik Individu,

Karakteristik

Pekerjaan,Karakteristik

Organisasi Terhadap Kepuasan Kerja dan Motivasi Kerja (Studipada Pengurus KUD di Kabupaten Sleman). Jurnal Manajemen danKewirausahaan, Vol. 11 tahun 2009

Arikunto, Suarsimi. 2012. Prosedur Penelitian Suatu Pendekatan Praktis. Jakarta: Rineka Cipta

As'ad, Mohamad. 2004. Psikologi Industri. Liberty: Yogyakarta.

Dona, E. (2016). Pengaruh

Perencanaan, Prosedur Dan

Pengawasan dan Komitmen

Organisasi Dalam Pelaksanaan

Anggaran Terhadap Kinerja

Pegawai Dinas Pekerjaan Umum 
Kota Pariaman. Jurnal Riset Manajemen dan Akuntansi (Jurmak), 23-35.

Dona, E. (2018). Analisis Motivasi Kerja Ditinjau Dari Lingkungan Kerja Kasus Karyawan LBPP Lia Payakumbuh. Jurnal KBP.

Ghozali, Iman. 2006. Aplikasi Analisis Multivariate dengan Program SPSS. Semarang: Badan Penerbit Universitas Diponegoro.

Ghozali, Imam. 2009. Aplikasi Analisis multivariat dengan program SPSS.Semarang : BPUniversitas diponegoro.

Ghozali, Iman. 2011. Aplikasi Analisis Multivariate dengan Program IBM SPSS 19. Edisi Kelima. Universitas Diponegoro: Semarang

Grifin, R. W. 2003. Manajemen. Jakarta: Erlangga.

Gustisyah. Faktor-Faktor yang Mempengaruhi Motivasi, Skripsi tidak dipublikasikan, Universitas Diponegoro. Semarang

Handoko, Hani. 2008. Manajemen Personalia dan Sumberdaya Manusia. Edisi Kedua. Cetakan Keenam. BPFE. Yogyakarta.

Hasibuan. 2003. Organisasi dan Motivasi. Dasar Peningkatan Produktivitas. Jakarta: PT Bumi Aksara.

Hasibuan, Malayu. 2007. Manajemen Sumber Daya Manusia. Edisi
Revisi. Cetakan Kesepuluh. PT. Bumi Aksaran. Jakarta.

Hasibuan, Melayu, 2008, Manajemen Sumber Daya Manusia. Jakarta: PT. Bumi Aksara

Heru Susilo, Djamhur Hamid, dan Sagita Sukma Haryani. 2015.Pengaruh Kompensasi terhadap Motivasi Kerja dan Kinerja Karyawan PT. Telekomunikasi Indonesia, TBK Malang.

Husein, Nirza Marzuki dan Andrian Hady. 2012. "Pengaruh Lingkungan Kerja dan Karakteristik Individu Terhadap Kepuasan Kerja Karyawan Hotel Melati Di Kecamatan Banjarmasin Tengah". Jurnal Manajemen dan Akuntansi. Vol. 13. No. 1. April 2012. Hal. 35 44. Sekolah Tinggi Ilmu Ekonomi. Banjarmasin.

Luthans, Fred. 2006. Perilaku Organisasi 10th. Edisi Indonesia. Yogyakarta: Penerbit ANDI

Luthans, F. 2011. Organizational Behavior, An Evidence Based Approach, Twelfth Edition, McGraw Hill.

Mathis, Robert L, dan Jhon H. Jackson. 2006. Human Resource Management (Manajemen Sumber Daya Manusia). Edisi 10. Jakarta: Salemba Empat.

Nardo, R. Evanita, Syahrizal, S. (2018). Pengaruh Kepemimpinan Transformasional, Dan 
Lingkungan Kerja Non Fisik Terhadap Perilaku Inovatif. JEBI (Jurnal Ekonomi dan Bisnis Islam) 3 (2), 209-215

Nardo, R. Evanita, Syahrizal, S. (2019). The Effect of Transformational Leadership and Non Physical Work Environment on Innovative Behavior with Work Motivation as a Mediation For Employees of Tour And Travel Companies In West Sumatera. 2nd Padang International Conference on Education, Economics, Business and Accounting (PICEEBA-2 2018)

Susriyanti, S. Nardo, R. (2019). Pengaruh Fungsi Komunikasi Dan Kepuasan Kerja Karyawan Terhadap Pemberian Pelayanan Nasabah PT. BPR LPN Talawi Sakato. Jurnal Administrasi Sosial dan Humaniora 3 (2), 97111.

Putra, RY. Marlius, D. (2019). Pengaruh Pendidikan, Pengalaman Kerja dan Etos Kerja Terhadap Kinerja Pegawai Di KPN Batur. Academic Conference For Management 2.

Rivai, Veithzal dan Ella Juavani Sagala. 2008.Manajemen Sumber Daya Manusia. Jakarta

Robbin S, Judge T, 2009. Organizational Behavior, BY Pearson Education, Inc, Upper Saddle River, New Jersey, United states of America
Robbins, Stephen P. 2007. Perilaku Organisasied.10. Jakarta : PT Macanan Jaya Cemerlang.

Robbins, Stephen P. \& Timothy A. Judge. (2008). Perilaku Organisasi. Edisi 12. Jakarta : Salemba Empat.

Sekaran, Uma. 2006. Metodelogi Penelitian Untuk Bisnis. Jakarta: Salemba Empat.

Sekaran, Uma. 2009. Research Methods for Business Buku Kedua. Jakarta: Salemba Empat.

Siagian, Sondang P. 2003, Manajemen Sumber Daya Manusia, Jakarta: PT. Bumi Aksara.

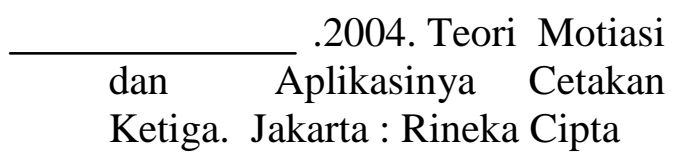

Sofyandi, H, dan Iwa Garniwa. 2007. Prilaku Organisasional. Yogyakarta: Graha Ilmu.

Sopiah, 2008, Perilaku Organisasional, edisi pertama, cetakan pertama, Penerbit : Andi, Yogyakarta

Sugiyono. 2005. Metode penelitian pendidikan : pendekatan kuantitatif, kualitatif, dan $R \& G$. Bandung. Alfabeta.

Sugiyono. 2014. Metode Penelitian Manajemen. Pendekatan: Kuantitatif, Kualitatif, Kombinasi, Penelitian Tindakan, Penelitian, Penelitian Evaluasi. Bandung. Alfabeta. 
Sutrisno, Edy. 2012. Manajemen Sumber Daya Manusia. Edisi 1. Cetakan Keempat. Prenada Media Group. Jakarta.

Thoha, M., 2003. Pengembangan Organisasi, Proses Diagnosa dan Intervensi, Jakarta: PT. Rajagrafindo Persada

Yudistira, D. S., \& Susanti, F. (2019). Pengaruh Motivasi Kerja Dan Budaya Kerja Terhadap Kinerja Karyawan Dinas Pemberdayaan Masyarakat Dan Desa, Pengendalian Penduduk Dan Keluarga Berencana Kabupaten Pesisir Selatan. https://doi.org/10.31227/osf.io/jk $54 \mathrm{~m}$

Mulyadi, H., \& Susanti, F. (2018). Pengaruh Penerapan Strategi Customer Relationship Marketing Terhadap Kepuasan Nasabah Pada PT. Pro Car International Finance Cabang Padang. https://doi.org/10.31227/osf.io/b hq $8 \mathrm{~d}$

Ridho, M., \& Susanti, F. (2019). Pengaruh Stres Kerja Dan Motivasi Kerja Terhadap Kepuasan Kerja Pada Karyawan Bank Mandiri Syariah Cabang Padang. https://doi.org/10.31227/osf.io/p a2cg

Lubis, A. Y. O., \& Susanti, F. (2019). Pengaruh Gaya Kepemimpinan Dan Kompensasi Terhadap Prestasi Kerja Karyawan (Studi pada PT Japfa Comfeed Indonesia (JCI) Tbk Devisi Fam 1. https://doi.org/10.31227/osf.io/7t

brg

Jamarnis, S., \& Susanti, F. (2019).

Pengaruh Harga Dan Periklanan

Melalui Internet Terhadap

Keputusan Pembelian Produk Sabun Merek Lux Pada Mahasiswa STIE "KBP" Padang. https://doi.org/10.31227/osf.io/x $\mathrm{z} 3 \mathrm{~d} 8$

Aldi, Y., \& Susanti, F. (2019). Pengaruh Stress Kerja Dan Motivasi Kerja Terhadap Prestasi Kerja Karyawan Pada PT. Frisian Flag Indonesia Wilayah Padang. https://doi.org/10.31227/osf.io/et $4 \mathrm{rn}$

Widodo, B. H., \& Susanti, F. (2019). Pengaruh Human Relation (Hubungan Antar Manusia), Lingkungan kerja Terhadap Etos Kerja karyawan (Studi Kasus Pada PT. Pelindo Teluk Bayur Padang https://doi.org/10.31227/osf.io/d $\mathrm{xm} 8 \mathrm{a}$

Junaidi, R., \& Susanti, F. (2019). Pengaruh Gaya Kepemimpinan Dan Budaya Organisasi Terhadap Kinerja Pegawai Pada UPTD Baltekkomdik Dinas Pendidikan Provinsi Sumatera Barat. https://doi.org/10.31227/osf.io/b zq75

Thoha, Miftah. 2007. Perilaku Organisasi: Konsep Dasar dan Aplikasi. Penerbit Rajawali, Jakarta.

Samosir, F., \& Magdalena, M. (2019). Effect Of Work Stress And Work Satisfaction Of Employees Performance Pt. Primatama Mulia 
Jaya Iv Koto Kinali Kecamatan Kinali Kab. Pasaman Barat. Https://Doi.Org/10.31219/Osf.Io/ Gjvry

Utami, R. S., \& Magdalena, M. (2020, March 23). Pengaruh Kebutuhan Aktualisasi Diri Dan Beban Kerja Terhadap Prestasi Kerja Karyawan Pada Dinas Perindustrian dan Perdagangan Sumatera Barat. Retrieved from osf.io/kdyca

F., \& Magdalena, M. (2019). Pengaruh Komunikasi Lisan Dari Dokter Hewan Terhadap Kepuasan Pelanggan Pada Produk Obat Di Pt Sanbe Farma Cabang Padang. Https://Doi.Org/10.31219/Osf.Io/ Rgs5

Fatra, O., \& Magdalena, M. (2020, March 23). Pengaruh Pengembangan Karier, Penempatan Jabatan dan Motivasi Terhadap Prestasi Kerja Pegawai Pada Kantor Camat Kubung. https://doi.org/10.31219/osf.io/ts9 $4 \mathrm{j}$ 